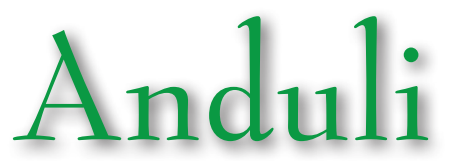

Revista Andaluza de Ciencias Sociales

ISSN: 1696-0270 • e-ISSN: 2340-4973

\title{
LA ALTERIDAD EN EL PENSAMIENTO DESCOLONIAL DE ENRIQUE DUSSEL
}

\section{ALTERITY IN THE DECOLONIAL THINKING OF ENRIQUE DUSSEL}

\author{
Esteban-Gabriel Sanchez \\ Universidad Nacional del Sur, Argentina \\ estebansanchez88@hotmail.com \\ https://orcid.org/0000-0002-6776-6866
}

\section{Resumen}

El descolonialismo latinoamericano tiene un lugar destacado en la crítica al eurocentrismo presente en las ciencias sociales y humanidades. Este trabajo plantea el problema de la Alteridad en el pensamiento descolonial de Enrique Dussel a través de la exegesis hermenéutica de tres categorías claves: exterioridad, trabajo vivo y víctima. El objetivo de esta investigación es determinar las continuidades y discontinuidades de la categoría de Alteridad en la obra del filósofo argentino-mexicano. Para el marco teórico-metodológico se utiliza la noción de actitud des-colonial y el enfoque hermenéutico-filosófico latinoamericano de la liberación. En las conclusiones se muestra que el concepto de alteridad aparece en la obra temprana de Dussel, asociada al lenguaje ético levinasiano. Mas tarde, en su obra madura, se evidencia un giro hacia una reflexión económica-material a fin de comprender históricamente la opresión y exclusión de los países periféricos.

Palabras claves: Dussel; giro decolonial; Otro; Latinoamérica; Filosofía de la Liberación; trabajo vivo; materialidad

\begin{abstract}
:
Latin American decolonialism has a prominent place in current criticism of Eurocentrism in the social sciences and humanities. This paper raises the problem of alterity in the decolonial thinking of Enrique Dussel through the hermeneutical exegesis of three main categories: exteriority, living work and victim. The purpose of this research is to determine the continuities and discontinuities of this problem in the theoretical work of the ArgentineMexican philosopher. As our theoreticalmethodological framework, we consider the notions of the de-colonial attitude and the Latin American hermeneuticphilosophical approach to liberation. In the conclusions, we show that the concept of alterity appears in Dussel's early work associated with Levinasian ethical language. Later, a shift towards an economic-material reflection is evidenced in his mature work as a means to historically understand the oppression and exclusion of peripheral countries.
\end{abstract}

Keywords: Dussel; de-colonial turn; alterity; Latin America; The philosophy of Liberation; living labor; materiality 


\section{Introducción y marco teórico}

Es menester elaborar una genealogía de los estudios descoloniales en Nuestra América, atender sucintamente no sólo a su conformación como campo disciplinar en las ciencias sociales y humanas contemporáneas sino también a sus diversas líneas teóricas en curso. En general, como señala Nelson Maldonado-Torres, podemos reconocer que la idea de descolonización se sucede sincrónicamente a los procesos de colonización (Maldonado-Torres, 2018). En términos disciplinares, es posible establecer al menos tres antecedentes teóricos de los enfoques descoloniales: el pensamiento anticolonial caribeño (Césaire, 2006; Fanon, 2009), la Filosofía de la Liberación latinoamericana (Ardiles et al., 1973; Dussel, 2008, 2011; Picotti, 1998) y los estudios poscoloniales de la India (Chakrabarty, 2008; Guha, 2002; Spivak, 2010). Si bien provienen de herencias teóricas diferenciables dichos antecedentes se vinculan en su capacidad de elaborar discursos críticos en torno al pensamiento occidental moderno y sus heridas en los cuerpos subalternizados. Los estudios descoloniales se insertan en el pensamiento social latinoamericano por medio de la Red Modernidad/Colonialidad que estaba compuesta por múltiples contradictorias perspectivas en torno a la relación entre colonialismo, modernidad y capitalismo a partir de conquista de América en 1492 y sus continuidades en los procesos latinoamericanos actuales (Castro-Gómez, 2019; Dussel, 2000, 2020; Grosfoguel, 2009, 2016, 2018; Lander \& Quintero, 2019; Lander et al., 2019; Maldonado-Torres, 2007; Mignolo, 2009a, 2009b; Aníbal Quijano, 2014; Aníbal Quijano et al., 2017).

Las fuertes críticas a los enfoques eurocéntricos, todavía dominantes en las ciencias sociales y humanas, han adquirido diversas manifestaciones teóricas y metodológicas dentro del pensamiento latinoamericano actual. En este sentido, la multiplicidad de respuestas que se han elaborado en el proceso de construcción y desarrollo del patrón de poder moderno/colonial se remontan a las historias y trayectorias de las resistencias de los pueblos conquistados a lo largo de los últimos cinco siglos. En el marco del pensamiento descolonial, la idea de descolonización se ha consolidado a través diversas modulaciones críticas hacia el "sistema-mundo capitalista/patriarcal occidental-céntrico/cristianocéntrico moderno/colonial” (Martinez Andrade \& Grosfoguel, 2013, p. 40). Como aclara Sirin Adlbi Sibai, dicho patrón de poder consiste en el sistema "internacional global intrínsecamente colonial, imperialista, patriarcal y racista que instituye e institucionaliza la sustracción y transferencia sistemáticas de los recursos materiales, culturales, epistémicos, espirituales y humanos de dos terceras partes del mundo" (Adlbi Sibai, 2016, p. 21). Nos proponemos aproximarnos al itinerario vivencial de Dussel y a su producción teórica en tanto revela el potencial crítico de la distancia (Said, 1996). En este punto, se recupera la experiencia represiva y exiliar del pensador mendocino y el modo de articulación de dicha experiencia, en tanto toma consciencia ética de su condición de latinoamericano y, asimismo, alimenta así la función estratégica que asume la práctica filosófica en el exilio.

\section{Materiales y métodos}

Nuestra indagación intentará pensar y tematizar la Alteridad desde las categorías de exterioridad, trabajo vivo y víctima en el pensamiento descolonial de Enrique Dussel. En este sentido, reconstruiremos la trayectoria intelectual del filósofo argentino-mexicano, por ello seguiremos lo propuesto por Nelson Maldonado-Torres, quien afirma que "la obra de Dussel es un conjunto de intervenciones y contribuciones sustanciales y provocadoras de carácter filosófico, histórico, y teológico a lo que podría llamarse el proyecto 
incompleto de la descolonización" (Maldonado-Torres, 2018, p. 316). Nos detendremos a examinar la actitud des-colonial' presente en la obra dusseliana teniendo en cuenta dos momentos: uno abstracto y otro concreto. Para ello, utilizaremos metodológicamente el enfoque hermenéutico-filosófico latinoamericano de la liberación (Dussel, 2018a).

La estructura de la presente investigación está compuesta por cinco secciones. En la primera se analiza el complejo recorrido intelectual de Dussel y sus diálogos con los principales referentes del pensamiento crítico, de cara a comprender su producción como una crítica fundamental al eurocentrismo. En la segunda sección, se analiza las nociones de Totalidad y exterioridad en el pensamiento ético levinasiano con la finalidad de evaluar la interpretación dusseliana de dichas nociones. En la tercera, se elabora una exegesis de la Alteridad por medio de las categorías exterioridad y Totalidad en el marco de la Filosofía de la Liberación. En la cuarta sección, se estudia la categoría de trabajo vivo en tanto la materialidad humana del pauper que se somete a la explotación capitalista. Luego, se examina la categoría de víctima desde los tipos concretos de interpelación de la materialidad humana viviente en comunidad. En la última sección se exponen las conclusiones alcanzadas en la presente indagación crítica.

Con la finalidad de comprender la meditación dusseliana acerca de la Alteridad y revalorizar su experiencia de vida podemos reconocer dos momentos en que lo latinoamericano impacta en su pensamiento, que denominaremos, el modo abstracto de la exterioridad y el modo concreto del trabajo vivo-víctima, podríamos decir también desde la reflexión y la extrañeza en su primer desplazamiento fuera de la Argentina y mientras realizaba estudios en Europa y luego desde su experiencia personal como exiliado latinoamericano en México.

\section{Los momentos de la actitud des-colonial dusseliana}

En el mencionado primer momento, Dussel comienza a abandonar su conciencia nacional y descubre ${ }^{2}$, de modo abstracto, su condición de latinoamericano en los años (1957-1961) de su formación doctoral en Europa, luego regresa a la Argentina y empieza a desarrollar su propio pensamiento. Posteriormente, el segundo momento se inicia en 1973 con la conformación del movimiento ${ }^{3}$ de la Filosofía de la Liberación ${ }^{4}$

1 Como señala Nelson Maldonado-Torres: "la idea de descolonización es tan vieja como la colonización moderna misma. Se trata primeramente no de una idea como tal, sino de un sentimiento y sentido de horror ante el despliegue de las formas coloniales de poder en la modernidad (...) La actitud des-colonial nace cuando el grito de espanto ante el horror de la colonialidad se traduce en una postura crítica ante el mundo de la muerte colonial y en una búsqueda por la afirmación de la vida de aquellos que son más afectados por tal mundo" (Maldonado-Torres, 2008b, pp. 66-67).

2 Dussel en su partida hacia Europa afirma: "toqué a una América Latina y a un Tercer Mundo que me habían sido absolutamente desconocidos. Yo deseaba con pasión ir a Europa, y yendo hacia ella había ya tropezado, descubierto, para siempre, el mundo periférico que había estado antes fuera de mi horizonte teórico y práctico" (Dussel, 2018a, p. 20).

3 Para una correcta caracterización de la filosofía de la liberación cabe destacar lo propuesto por Marcelo González y Luciano Maddonni: "respecto del riesgo de considerar a la producción argentina como originadora exclusiva, cronológicamente primera y capturadora de la totalidad del abordaje filosófico en torno a la dupla dependencia-liberación en América Latina. Los aportes de Leopoldo Zea en México, de Augusto Salazar Bondy en Perú, de Ignacio Ellacuría en El Salvador, de Franz Hinkenlammert en Costa Rica y del 'Grupo de Bogotá' en Colombia, son algunos ejemplos de otras expresiones claves para una mirada complexíva." (González \& Maddonni, 2018, p. 65).

4 De ahora en más nos referiremos al movimiento de la Filosofía de la Liberación con las siglas FL. 
en las Cuartas Jornadas Académicas que se realizan en la Facultad de Filosofía de la Universidad de El Salvador (San Miguel, Argentina). En la noche del 2 de octubre de 1973 Dussel fue víctima de un atentado bomba en su casa perpetrado por la Alianza Anticomunista Argentina a través del 'comando Rucci', que era un grupo de derecha del sindicalismo metalúrgico mendocino; lo acusaban de marxista y de corromper a la juventud (Dussel, 2018b). El 31 de marzo de 1974 es expulsado como profesor junto a 17 colegas de Facultad de Filosofía y Letras de la Universidad Nacional de Cuyo (UNCuyo), dichas expulsiones formaban parte de la "limpieza ideológica" de las universidades nacionales llevada a cabo por el entonces Ministro de Educación Oscar Ivanissevisch ${ }^{5}$. A partir de estos acontecimientos, Dussel se encuentra forzado a exiliarse en México desde 1975 y posteriormente no regresa a nuestro país, incluso con la restitución de la democracia ante la imposibilidad recuperar sus cargos docentes. En este segundo momento, Dussel toma conciencia ética, de modo concreto, de su condición de latinoamericano en el marco del sistema-mundo:

La función estratégica de la filosofía en el exilio tiene en primer lugar un carácter de autocrítica, después una exigencia de perfilar mejor sus categorías de interpretación, para por último formular positivamente las articulaciones de un proyecto de liberación latinoamericano, a fin de no sólo incluir a su país de origen (desde donde se salió para el exilio) sino también el país hermano donde se habita. El común destino latinoamericano nos permite, cuando seguimos pensando filosóficamente en América latina, formular una estrategia común (...) es decir, una «filosofía de la liberación» (Dussel, 2012a, pp. 111-112).

En efecto, la función estratégica de la filosofía en el exilio exterior ${ }^{6}$ no sólo representa la internacionalización del locus enuntiationis latinoamericano sino también es el espacio para la producción y recreación filosófica propia. Tal función estratégica del intelectual no sólo constituye la toma conciencia ética individual sino también, como afirma Edward Said, "darle un alcance humano más amplio a los sufrimientos que haya podido experimentar una nación o raza particular, de asociar esa experiencia con los sufrimientos de otros" (Said, 1996, p. 57).

Asimismo, para caracterizar historiográficamente la obra de Enrique Dussel seguiremos lo propuesto por (Sánchez \& Verdini Aguilar, 2019), quienes distinguen cinco momentos: en el primero el filósofo está vinculado a la fenomenología-hermenéutica de Heidegger y Ricoeur en la década del 60'. El segundo momento es el ético

5 Como señala la filósofa Adriana Arpini "En Argentina, el 14 de agosto de 1974, poco después de la muerte del entonces presidente, Gral. Juan Domingo Perón, asumió como Ministro de Educación Oscar Ivanissevisch, en reemplazo de Jorge Taiana. Se mantuvo en la cartera durante un año, hasta el 11 de agosto de 1975. El objetivo explícito de su misión era 'eliminar el desorden' en la universidad y producir la 'depuración ideológica' (Izaguirre, 2009; Bonavena y otros, 2007). Durante ese período se incrementaron las muertes y desapariciones, así como las cesantías de docentes, estudiantes y personal de apoyo académico de las universidades argentinas, y se sucedieron atentados contra quienes eran sospechados de sostener y difundir ideas marxistas y/o subversivas. Así comenzó un nuevo proceso de vaciamiento de las universidades y de exilio de la razón -tal vez el más doloroso de la historia argentina-. Muchos partieron con rumbo a Europa, Estados Unidos o diversos países de América Latina -'exilio exterior'-, otros quedaron en el país separados de sus cargos o imposibilitados de acceder a la universidad (ni como docentes, ni como graduados, ni como alumnos) o a otros cargos públicos y condenados al silencio -'exilio interior"' (Arpini, 2017, p. 339).

6 Como señala la filósofa mendocina Adriana Arpini: "el discurso filosófico del exilio maduró, desde el exterior, como denuncia de la violencia y revisión crítica de las propias categorías de análisis filosófico, político y social. Renovación categorial y metodológica indispensable para la comprensión de una realidad latinoamericana heterogénea y conflictiva" (Arpini, 2017, p. 341). 
fenomenológico asociado a la influencia de Levinas y la etapa de constitución de su ética de la liberación latinoamericana, entre los años 1970-1975. En el tercer momento desarrolla la Filosofía de la Liberación ${ }^{7}$ y se dedica al estudió sistemático de Marx durante los años 1976-1990. En el cuarto momento dialoga con la Ética del discurso de Karl-Otto Apel, a lo largo de la década del '90. En el quinto momento, todavía en curso, se relaciona con el giro de descolonial, a partir de la publicación de su obra 1492: El encubrimiento del Otro. Hacia el origen del "Mito de la modernidad»" [1992], junto a Aníbal Quijano, Ramón Grosfoguel, Karina Ochoa Muñoz, Nelson Maldonado-Torres, Walter Mignolo, entre otros. Sin embargo creemos que es necesario elaborar una periodización más exhaustiva para no caer una visión evolutiva de los diversos momentos como si las etapas de su pensamiento se sucedieran por rupturas (García Ruiz, 2003). Por esta razón consideremos imperioso comprender el desarrollo y la elaboración filosófica de Dussel por momentos alternativos de continuidades y discontinuidades, en el cual se dan giros o desplazamientos temáticos. Observamos que los momentos se van subsumiendo al interior de su sistema. Nuestra hipótesis principal reconoce dos grandes giros en el pensamiento del filósofo mexicano: el primer giro es el de la ética levinasiana a partir de la cual se aproxima abstractamente a la Alteridad. El segundo giro es la historicidad concreta del pauper (pobre) desde América Latina. Dussel recupera al Otro en el análisis marxiano en torno al capitalismo para la reconstrucción de la génesis histórica de la modernidad con la invasión de América (Sánchez, 2018).

En resumen, la problemática central de la actitud des-colonial de Dussel gira en torno a la reflexión ética sobre la Alteridad. Encontramos dos grandes momentos en su pensamiento. En el primer período, entre 1969 y 1975, se avoca al estudio de la ética levinasiana y recurre a una concepción abstracta de la Alteridad para elaborar su ética latinoamericana desde una revisión crítica de la ontología moderna. El segundo momento comienza en 1976 y se caracteriza por un desplazamiento hacia una concepción positiva de Marx ${ }^{9}$. Desde esta nueva perspectiva, su reflexión parte de la materialidad negada del Otro como pauper (pobre) en América Latina en el decurso del patrón de poder moderno/colonial. A continuación, revisaremos de modo sucinto el pensamiento ético de Emmanuel Levinas a fin de comprender la lectura de dusseliana de las categorías de Totalidad y exterioridad.

7 Cabe distinguir la obra Filosofía de la Liberación [1976] de Dussel y el movimiento de la Filosofía de la Liberación como corriente de la Filosofía Latinoamericana, integrado por figuras como Arturo Andrés Roig, Franz Hinkelammert, Rodolfo Kusch, Juan Carlos Scannone, Horacio Cerutti Guldberg, entre otros (Arpini, 2016).

8 En la mencionada obra Dussel expone acerca de la Trans-modernidad como proyecto futuro de liberación, una nueva era para toda humanidad (Dussel, 2008). La Trans-modernidad es categoría sumamente productiva para los autores del giro descolonial (Acosta, 2019; Bautista, 2014; Castro-Gómez, 2019; Grosfoguel, 2008; Maldonado-Torres, 2008a).

9 Tal como afirma Dussel: "la posición de «exterioridad» (como filosofía, cultura popular, economía latinoamericanas con respecto a Estados Unidos o Europa) en cuanto «pobres» (es decir, desde una economicidad antropológica y ética) (...) Hipótesis que aplicada a una relectura de Marx desde 1976 puede dar como resultado una nueva interpretación de la crítica ética de la economía política" (Dussel \& Apel, 2013, p. 144). También Raúl Fornet-Betancourt sostiene que "a partir del exilio mexicano [Dussel] va a girar precisamente en torno de una relectura sistemática de Marx que le llevará a descubrir el planteamiento marxiano como marco teórico complementario (...) una fase que caracteriza por un diálogo constructivo con Marx" (Fornet-Betancourt, 2001, p. 325). 


\subsection{Totalidad y exterioridad en el pensamiento levinasiano}

Desde la perspectiva de Emmanuel Levinas, la filosofía occidental se caracteriza por ser una filosofía de Totalidad (Totalité) que domina a la Alteridad del Otro (Autrui). La Totalité establece una relación de sometimiento con el Autrui, no lo considera como dis-tinto. El Autrui no es Otro en tanto Otro sino un mero medio para lógica de la mismidad. El Autrui queda reducido, asfixiado por lo Mismo (Même). La tarea ética de la metafísica consiste en recuperar y cobijar al Autrui en tanto infinito e inagotable. La Alterité del Otro es absolutamente trascendente y anterior a toda razón. El llamado (vocare) y la provocación (pro-vocare) del Autrui tiene que ser escuchada (audire) desde la exterioridad que supone la epifanía de su rostro (Levinas, 2002). Vocare es el llamado a la solidaridad de asumir responsablemente el deseo metafísico por el Otro como otro, esto es, como agente activo de su propia existencia. Dicha experiencia es infinita porque nos desborda, no puede ser agotada desde la dimensión del pensar y representar. Abrirse al Otro no es una declaración volitiva sino un ejercicio permanente que nos interpela prácticamente. Levinas elabora una ética pre-ontológica que se asienta en el rostro del Otro. Relacionarse desde el respeto sagrado al Autrui funda una nueva vivencia de la existencia.

En general, la ontología occidental, como ámbito del ser, interpretó al conocer desde la preeminencia de la visión. El filósofo lituano-francés afirma que "la relación fundamental del ser, en Heidegger, no es la relación con el otro, sino con la muerte, donde se denuncia todo lo que hay de inauténtico en la relación con el otro, pues uno muere solo" (Levinas, 2000, p. 53). Ahora bien, la experiencia radical del Autrui como tal se erige como un mandato ético que ansía destruir el imperio de la Totalité. Por ello, la ética tiene que entregarse absolutamente a la escucha e interpelación del Autrui en tanto Otro. La obediencia inalienable del principio ético no matarás nos exhorta a cuidar respetuosamente las diferentes manifestaciones de la exterioridad:

La proximidad del Otro, la proximidad del prójimo, es en el ser un momento ineluctable de la revelación, de una presencia absoluta (...) que se expresa. Su epifanía misma consiste en solicitarnos por su miseria en el rostro del Extranjero, de la viuda y del huérfano (Levinas, 2002, p. 101).

La meditación ética de Levinas está marcada por las trágicas experiencias totalitarias del nazismo y su maquinaria de muerte. El ámbito de la ética consiste en ponerse en relación al ser desde un más allá de la Totalité. Esto es, establecer una relación desde la trascendencia y excedencia inherente a la exterioridad, siempre anterior a la Totalidad e irreductible a ella: el rostro del Autrui (Levinas, 2000). El aparecer del rostro nos invoca a cuestionar la Totalité y denunciar la injusticia cometida con la viuda, el extranjero, y huérfano. Levinas diferencia la anterioridad de la ética del Autrui respecto al dominio e injusticia de la Totalité, esto es, escinde irreconciliablemente el ámbito ético que se refiere al Otro del ámbito político que representa a la Totalidad. El autor de Totalidad e infinito afirma que el "arte de prever y ganar por todos los medios la guerra - la política- se impone, en virtud de ello, como el ejercicio mismo de la razón. La política se opone a la moral, como la filosofía a la ingenuidad" (Levinas, 2002: 47). La política es entendida como una forma de la guerra que, mediante el cálculo y dominio racionalizado, reduce y reifica al Otro. Es decir, la Totalidad refiere al ámbito político moderno que somete y arrastra al Autrui a la lógica de mismidad. Al postular dicha escisión dicotomiza, por un lado, la singularidad del Autrui y la maquinaria opresiva de la Totalité, por el otro. A partir de las indicaciones levinasianas cabe preguntarse: ¿cómo reconocer la facticidad del Otro? O mejor dicho, ¿cómo 
se concretiza históricamente el Otro en América Latina? Para responder suficientemente estos interrogantes debemos remitirnos a lectura dusseliana de la ética de Levinas.

\subsection{Interpretación latinoamericana de la categoría de exterioridad}

A continuación expondremos la peculiar reapropiación de Dussel sobre la categoría de exterioridad. Dicha categoría constituye el principio rector de su ética latinoamericana de la liberación, seguiremos lo indicado por Maldonado-Torres:

La filosofía de la liberación dusseliana (...) adquiere su sentido pleno dentro de este cuadro histórico uno que toma en cuenta tanto la historia del pensamiento en América Latina como los diálogos y las vertientes de pensamiento descolonizador que se han dado en distintas partes del mundo y que guardan relación entre sí (Maldonado-Torres, 2018, pp. 315-316).

Como vimos en la introducción, caracterizamos historiográficamente la obra de Dussel en cinco períodos. En el primero período, el filósofo latinoamericano se encuentra marcado por la fenomenología-hermenéutica de Heidegger y Ricoeur. En este momento, la reflexión dusseliana está centrada en el núcleo ético-mítico del pensamiento helénico y semita. En estos años, Dussel tiene una intuición originaria que oficia de hilo conductor de su reflexión en los años posteriores, incluso antes de estudiar a la obra de Levinas. En 1959, en su estancia en Israel, junto al teólogo Paul Gauthier Dussel escribe -en una carta a su amigo Esteban Fontana:

Algún día deberemos escribir la Historia de América Latina desde el otro lado, desde abajo, desde los oprimidos, desde los pobres (...) Esta era la 'experiencia originaria’ que se instalaba debajo de toda transformación epistemológica, teórica, filosófica o hermenéutica futura" (Dussel, 2018a, pp. 23-24).

Ahora bien, dicha experiencia originaria se constituye como una reflexión fundamental de todo el pensamiento dusseliano, es decir, la intuición originaria se expresa en la categoría de exterioridad. Con respecto al mencionado primer giro Dussel accede a la obra Totalité et Infini de Levinas a través de Juan Carlos Scannone (Beorlegui, 2010). En 1970, Scannone regresa a la Argentina de su estancia doctoral en Alemania y comparte la ética levinasiana con Enrique Dussel en la Universidad del Salvador (sede de San Miguel). Por su parte, el filósofo mendocino sostiene que dicha obra "me despertó del sueño ontológico (heideggeriano y hegeliano)" (Dussel, 2012c, p. 13). De este modo, se distancia de la ética ontológica vinculada a Heidegger y Ricoeur para desarrollar la preocupación nodal de la FL: la opresión de los pueblos de nuestra América desde una crítica de la historia universal. En palabras del filósofo mexicano:

¿Por qué Levinas? Porque la experiencia originaria de la Filosofía de la Liberación
consiste en descubrir el "hecho» masivo de la dominación, del constituirse una
subjetividad como "señor» ante otra subjetividad como "oprimida», pero ahora
en el plano mundial (desde el comienzo de la expansión europea en 1492: hecho
constitutivo originario de la «Modernidad», imposible de ser descubierto por E. Le-
vinas.) Centro-Periferia en el mercado mundial; en el plano nacional (élites-masas,
burguesía nacional —clase obrera y pueblo); en el plano erótico (varón-mujer); en
el plano pedagógico (cultura imperial, elitaria versus cultura periférica, popular,
etc.): en el plano religioso (el fetichismo en lodos los niveles); en el nivel racial (la
discriminación de las razas no-blancas), etc. Esta "experiencia originaria» vivi-
da por todo latinoamericano aun en las aulas universitarias europeas de filosofía 
como ser colonial quedaba bien indicada en la categoría de Autrui (otra persona como Otro) como pauper. (Dussel, 2018a, pp. 33-34)

En efecto, la apropiación dusseliana del pensamiento del filósofo lituano-francés posibilita el desplazamiento de la ontologia a la ética: el ámbito de la ética es siempre preeminente y anterior al de la ontologia, pues en él se manifiesta la Alteridad. En estos años, la producción intelectual Dussel se corresponde con el segundo momento indicado, en el cual el filósofo argentino elabora una ética fenomenológica latinoamericana en los años 1970-1975. Luego, en 1976 comienza a desarrollar sistemáticamente la Filosofía de la Liberación asociada al tercer momento de su obra.

De esta manera, el influjo de la ética levinasiana se revela en la aspiración incesante de trascender el eurocentrismo característico de la modernidad europea. El ámbito de la Alteridad es anterior y trascendente a la ontología. La anterioridad del Otro que interpela "constituye la posibilidad del 'mundo' o del soi-même como reflexivamente digno, que se toma el fundamento del acto de justicia hacia el Otro (...) [aquí] la Filosofía de la Liberación da la razón a Levinas" (Dussel, 2018a, p. 35). En la filosofía moderna el mundo aparece como la Totalidad que obtura la apertura al Otro, la superación de la mismidad se efectúa por la descripción de los diversos aspectos de la Alteridad. La ontología piensa que el mundo es lo primordial y el fundamento de toda relación posible: "el mundo es la totalidad fundamental; es la totalidad de totalidades (...) cuando nos referimos a totalidad, sin otra indicación, hablamos de mundo" (Dussel, 2011, p. 53). No obstante, dicha Totalidad no está absolutamente totalizada, cerrada sobre sí misma puesto que emerge el Otro. La exterioridad no es pensada en el sentido de un afuera de la totalización, sino como una realidad inmanente a él pero incorporada bajo múltiples formas. La irrupción del Otro puede ser pensada desde una doble vía radicalmente opuesta. La primera consiste en incorporar a lo otro en lo mismo como diferencia: "lo diferente es lo arrastrado desde la identidad, in-diferencia originaria o unidad hasta la dualidad. La di-ferencia supone la unidad: lo Mismo" (Dussel, 2014a, p. 102). Las filosofías de la diferencia quedan apresadas dentro de la lógica de la Totalidad puesto que piensan lo otro reduciéndolo a lo mismo. La segunda vía piensa a lo Otro en lo mismo como distinción:

Lo dis-tinto (...) indica mejor la diversidad y no supone la unidad previa: es lo separado, no necesariamente procedente de la identidad que como Totalidad los comprende (...) la dis-tinción podrá ser vivida diversamente: como a-versión o con-versión al Otro, y en ello consistirá toda la eticidad de la existencia (Dussel, 2014a, p. 102).

Ahora bien, la Filosofía de la Liberación busca atravesar la Totalidad, es decir, superar la ontología desde la exterioridad por medio de la distinción ana-léctica. Acercarnos al Otro como tal es un aproximarse, acortar la distancia que nos separa. Dicha aproximación no es acercarnos para ver o tomar al Otro como un objeto (proxemia). El aproximarse es anterior a toda dominación totalizadora, es un acercamiento respetuoso, tal como afirma Dussel, "se trata no de 'lo Mismo', ni siquiera de 'lo otro' como di-ferencia óntica en 'lo Mismo'; se trata de 'el Otro' que es originariamente dis-tinto, sin unidad ni identidad previa (Dussel, 2014a, p. 123). El ser constituye el fundamento ontológico del mundo dado. Éste es lo mismo que la Totalidad vigente. La moral sustenta el mundo actual como natural y dado, no lo cuestiona sino que lo legitima como el único posible. En relación al sistema imperante se le establece la exterioridad, un no-ser relativo a dicho sistema. En definitiva, Alteridad está más allá de la ontología, es decir, es siempre transcendente al sistema moral vigente. En dicho más allá se revela la proximidad del rostro del Otro. En este sentido, la ética 
nos posibilita la mostración del cara-a-cara de la exterioridad como un Otro. Por lo tanto, Dussel diferencia lo moral de lo ético, es decir, separa a la totalidad de la ética. La primera constituye el mundo como lo moralmente dado, dominante y legítimo. La segunda se instala desde afuera del mundo dado, lo trasciende por la evocación pro-vocadora del oprimido en su desnudez. La ética es trans-ontológica porque critica la Totalidad vigente y nos incita a oír la voz del Otro que clama por las injusticias sufridas.

Asimismo, podemos pensar que en la última dictadura cívico-militar de la Argentina el reclamo de memoria, verdad y justicia de las Madres y Abuelas de Plaza de Mayo se constituyó como un acto ético por excelencia. La búsqueda incansable de justicia de los organismos de derechos humanos quebró el orden moral vigente instaurado por el gobierno militar y los medios de comunicación, cómplices ideológicos del régimen. El pedido de justicia invoca a la exterioridad del sistema, trae a la presencia la ausencia de los desaparecidos. En cada una de las fotografías de los 30.000 desaparecidos se muestra el cara-a-cara de la Alteridad. La realidad de su ausencia niega éticamente la totalidad totalizada.

Por su parte, Levinas sostiene que la exterioridad del Otro se expresa en el huérfano, la viuda y el extranjero, sin embargo permanece en un lenguaje metafísico abstracto que le imposibilita pensar la particularidad histórica de la dominación ya que escinde el ámbito ético del político. Es decir, tematiza la experiencia primordial del encuentro con la Alteridad pero no logra formular sus mediaciones:

Levinas habla siempre que el Otro es 'absolutamente' otro. Tiende entonces hacia la equivocidad. Por otra parte, nunca ha pensado que el Otro pudiera ser un indio, un africano, un asiático. El Otro, para nosotros, es América Latina con respecto a la Totalidad europea; es el pueblo pobre y oprimido latinoamericano con respecto a las oligarquías dominadoras y sin embargo dependientes (Dussel, 2014b, p. 161).

En cambio, la Filosofía de la Liberación se encarga de articular diversos tipos de mediaciones (erótica, pedagógica, política, histórica, etc.) que se establecen entre la exterioridad y la Totalidad. La propuesta de Dussel buscar suturar la escisión leviasiana entre lo ético y lo político a través de las mediaciones que tiene la exterioridad del Otro como pauper en América Latina. En el siguiente apartado expondremos resumidamente la dimensión económica y material de la actitud des-colonial dusseliana para comprender la Alteridad en tanto trabajo vivo y víctima.

\subsection{Las categorías de trabajo vivo y de víctima como la vida negada por el sistema vigente}

\subsubsection{El trabajo vivo como dimensión económica}

Ahora bien, la reflexión económica-material de Dussel se elabora a través de una apropiación de la categoría de trabajo vivo de Karl Marx. En este sentido, Alberto Parisí aclara que "el «trabajo vivo» redefine (...) el contenido teórico de la exterioridad más allá de Levinas" (Parisí, 2005, p. 193). Para caracterizar la interpretación de Dussel sobre el pensamiento marxiano seguiremos lo propuesto por (Löwy, 2007). Según el pensador brasileño, podemos reconocer dos tendencias antagónicas para caracterizar la relación entre modernidad y capitalismo en América Latina. La primera corriente es denominada "excepcionalismo indo-americano", y tiende a enfatizar la singularidad histórico-cultural de América Latina y su estructura social. La segunda corriente es el "eurocentrismo" y se limita a aplicar mecánicamente el modelo de desarrollo histórico europeo hacia América Latina. Sin embargo, ambas tendencias comparten una visión pesimista con respecto a la superación de la modernidad 
capitalista en América Latina. La apuesta teórica de Dussel pretende superar ambas tendencias a través de una doble operación. Por un lado, crítica al eurocentrismo como una ideología que universaliza abstractamente el desarrollo europeo moderno hacia el resto del sistema-mundo. Y por el otro, elabora una crítica ética al proceso de producción y reproducción del capital, puesto que piensa en la historia desde la perspectiva de los pobres.

En 1976, Dussel ante las amenazas de muerte se encuentra forzado a exiliarse y se radica en México. En el marco de la crisis del marxismo ${ }^{10}$ el esfuerzo de renovación teórica de la obra marxiana desarrollado por Dussel tiene en Nuestra América dos principales interlocutores, por un lado, el althusserianismo antihumanista ${ }^{11} \mathrm{y}$, por el otro, el marxismo humanista entendido como filosofía de la praxis (Ortega Reyna, 2019). En palabras de Dussel "en Europa la crisis del marxismo es 'académica' y 'política'. En la periferia su pertinencia es 'económica' (...) 'Nuestro' Marx se sitúa, en cambio, en el nivel de las necesidades vitales básicas: es un Marx económicoantropológico, ético" (Dussel, 2007, p. 268).

Por lo tanto, Dussel relabora las actitudes des-coloniales presentes en el pensamiento marxiano para entender la dependencia de los países periféricos ${ }^{12}$. A partir de ese momento, inicia el segundo giro en su obra que consiste en comprender la génesis histórica de la modernidad desde Otro como pauper. El filósofo latinoamericano empieza a elaborar sistemáticamente la Filosofía de la Liberación y se dedica al estudio de la obra completa (MEGA2) de Karl Marx, a fin de desarrollar la dimensión económica de su sistema filosófico. Según Dussel su lectura latinoamericana de Marx responde a cuatro razones:

En primer lugar, por la creciente miseria del continente latinoamericano (que no ha cesado de empobrecerse, hasta llegar a una epidemia de cólera en esos tiempos como fruto de la contaminación, marginalidad y desnutrición acelerada de la mayoría del pueblo latinoamericano). El «pobre», en la «exterioridad» del sistema de producción y distribución, es el «hecho» más brutal (...) En segundo lugar, para poder efectuar una crítica del capitalismo causa de una tal pobreza, aun antes de que, aparentemente triunfante en el Norte (más desde noviembre de 1989), se mostrara que fracasa en el 75\% de la Humanidad: en el Sur (África. Asia, América Latina). En tercer lugar, porque la Filosofía de la Liberación debía desplegar una

10 Como señala Michael Löwy: "El término 'crisis del marxismo' es más bien un fórmula periodística que un concepto teórico; describe el hecho de que, en ciertos países capitalistas avanzados, sectores significativos de la intelligentsia de izquierda, de origen stalinista y/o maoísta, bajo el impacto simultáneo de la disidencia en la URSS y en Europa Oriental (especialmente las revelaciones de Soljenitsin en el Archipiélago Gulag) y de la crisis del maoísmo en China, han conocido una profunda desmoralización y desorientación, que se manifiesta en particular por el rechazo — a partir de mediados de los años 70 — del marxismo (...) para salir de esta crisis, el marxismo no puede limitarse a repetir de manera ritual algunas citas de Marx y de Engels, según el modelo típico-ideal del molino de rezos budista; necesita renovarse y actualizarse, a través de un proceso de reflexión crítica (y autocrítica) sobre la realidad social actual" (Löwy, 1994, pp. 3-5).

11 En este sentido, Dussel aclara que "al escribir esta obra [Método para una filosofía de la liberación], en 1973, criticábamos al Marx althusseriano de la época. Después hemos podido estudiar a Marx detalladamente y nuestras conclusiones son exactamente las contrarias" (Dussel, 2012b, p. 11).

12 Cabe aclarar que nos referimos a la interpretación dusseliana sobre Marx en tanto insumo teórico para tematizar la dependencia de América Latina en el marco de la geopolítica del sistemamundo moderno/colonial. La presente investigación no pretende abordar el problema del colonialismo en la obra del filósofo alemán. En torno a dicho problema pueden consultarse las siguientes obras: (Marx, 2018, 2019; Marx \& Engels, 1979). 
económica y política precisas, claras, firmes — para posteriormente poder afianzar también la pragmática, como subsunción de la analítica. En cuarto lugar, porque, para poder superar el «dogmatismo» (marxista-leninista de la época) (ya que había comenzado a tener muv frecuentes contactos en Cuba, Alemania Oriental y la Unión Soviética, con las Academias de Ciencia), era necesario leer directa y seriamente a Marx mismo para afianzar la izquierda latinoamericana (Dussel, 2018a, pp. 48-49)

En consecuencia, la económica dusseliana se refiere a la lógica de reproducción del trabajo vivo en el capitalismo, por ello la pobreza es entendida como la imposibilidad de la reproducción vital humana. El capital es concebido como el sistema vigente que subsume todas las formas de vida existentes en la búsqueda insaciable de ganancia. En términos económicos, el trabajo vivo respecto al capital toma la figura del pauper. En palabras de Dussel, "el trabajo vivo, el trabajador mismo en su carnalidad disponible es 'el otro' absoluto que enfrenta al capital (...) es 'alteridad': ser-otro en tanto distinto a la totalidad establecida, dominadora, existente desde sí y por sí: el capital” (Dussel, 2010, p. 339).

Esto quiere decir que el ser de la totalidad se fundamenta en la extracción de la energía vital del trabajador, que es la que crea valor desde la absoluta intemperie de su existencia: "el trabajador no tiene valor (...) porque es la fuente creadora de dicho valor: es la exterioridad a todo posible sistema económico de explotación" (Dussel, 2011: 224). Según Dussel, la ética marxiana constituye una ética de la vida, debido a que es una crítica-ética del sistema vigente desde la negatividad del trabajo vivo. Se evidencia que la vida del hombre, en las relaciones sociales de producción capitalistas, se presenta de manera empobrecida y pauperizada.

\subsubsection{La víctima en la edad de la mundialización y exclusión}

Posteriormente, Dussel publica Ética de la Liberación en la edad de la globalización y la exclusión ${ }^{13}$ [1998] como resultado de extensa discusión con la Ética del Discurso de Karl-Otto Apel y de Jürgen Habermas; dicha obra puede considerarse como su obra más relevante ${ }^{14}$. A continuación, expondremos sintéticamente el principio material universal de toda ética con el propósito a comprender a la Alteridad desde la categoría de víctima.

Dicho principio consiste en "la obligación de producir, reproducir y desarrollar la vida humana concreta de cada sujeto ético en comunidad" (Dussel, 1998, p. 91), entendiendo la materialidad universal de la vida no sólo en tanto vida humana, sino también en la relación que el hombre establece con la naturaleza en general. El principio material tiene, en síntesis, tres niveles interrelacionados: el primero es su descripción ética (pre-ontológica). El segundo refiere a su obligación o explicación deontológica (deber-vivir). Por último, el tercero refiere a su aplicación o validez intersubjetiva en el ámbito de la comunidad. Todas las formas sociales que el hombre construye para posibilitar la vida en común tienen como contenido último a la vida humana del sujeto ético. El criterio de verdad práctico por el cual el hombre media su realidad es su vida misma. La vida humana se encuentra acotada entre los frágiles márgenes de la necesidad de nutrirse necesariamente para no perecer. Como corporalidad viviente, el hombre es un ser fisiológicamente necesitado.

13 De ahora en más nos referiremos a esta obra como Ética de la Liberación.

14 Como indicamos anteriormente en la introducción, el dialogo con la Ética del Discurso realizado durante la década del ' 90 se corresponde con el cuarto momento de la obra de Dussel. 
Según el filósofo mendocino, la materialidad entendida como comunidad de vida (Lebensgemeinschaft) es el núcleo de la fundamentación de la Ética de la Liberación. Esta concepción de la materialidad humana en tanto actividad vital consciente permite elaborar una propedéutica del criterio material universal de toda ética. Esta propedéutica no pretende construir una ciencia óntica de la vida en general sino que aspira a contribuir en la exposición -de los criterios pre-ontológicos: éticos- del contenido mismo de la vida en común. Hasta aquí hemos expuesto el aspecto descriptivo del principio material universal. Ahora nos detendremos en su obligación efectivamente ética. El hombre, en tanto ser autoconsciente, tiene la responsabilidad intransferible de su propia conservación. La obligación vital de perseverar en la existencia no implica éticamente, como postula el liberalismo, que cada sujeto debe actuar guiado por el fin egoísta de su propio beneficio individual sin considerar a los otros. La necesidad reproductiva del ser viviente no se encuentra escindida del actuar ético, que nos exige ser solidario con los demás. De este modo, la verdad práctica del querer vivir se convierte en un compromiso ético, en un deber-vivir que aspira a incluir todas las manifestaciones de la vida en la Tierra. En efecto, el actuar ético debe realizar el principio material universal para cada sujeto humano en su Lebensgemeinschaft, cuya referencia última sea la totalidad de lo viviente. Por último, el criterio de aplicación del principio material universal se trata de la validez intersubjetiva por la cual la acción ética se conduce y se mediatiza en fines, normas y valores de una comunidad. El principio material tiene una preminencia lógica, es decir, de la dimensión descriptiva, respecto de su aplicación. Ahora bien, Dussel aclara que entiende por la Alteridad en tanto víctima:

El Otro [es] (...) la/el otra/o mujer/hombre: un ser humano, un sujeto ético, el rostro como epifanía de la corporalidad viviente humana; será un tema de significación exclusivamente racional filosófico antropológico (...) el Otro no será denominado metafórica y económicamente bajo el nombre de "pobre». Ahora, inspirándonos en W. Benjamin ${ }^{15}$, lo denominaré «la víctima»-noción más amplia y exacta (Dussel, 1998, pp. 16-17).

La Ética de la Liberación procura afirmar la vida negada de la víctima de la explotación y exclusión en la fase actual del capitalismo. Habiendo puesto de manifiesto las diversas facetas del principio material universal podemos articularlo a continuación

15 Dussel indica que se inspira en las Tesis sobre la historia y otros fragmentos de Walter Benjamin para formular la categoría de víctima. Es menester señalar que la noción de víctima como tal no aparece ni una vez en esa obra del pensador alemán. Sin embargo, podría considerarse que la noción de vencidos quizás sea un equivalente semántico de la de víctima, puesto que los vencidos son las víctimas del desarrollo del continuum de la historia. En este sentido, Benjamin afirma en la tesis XII: "El sujeto del conocimiento histórico es la clase oprimida misma, cuando combate. En Marx aparece como la última clase esclavizada, como la clase vengadora, que lleva a su fin la obra de la liberación en nombre de tantas generaciones de vencidos" (Benjamin, 2009, p. 25).

Cabe aclarar que Enzo Traverso, en su obra Melancolía de izquierda, retoma a Benjamin para distinguir los términos víctima y vencidos: "A diferencia del humanitarismo hoy dominante, que sacraliza la memoria de las víctimas y en su mayor parte pasa por alto o rechaza sus compromisos, la melancolía de izquierda siempre se concentró en los vencidos. Percibe las tragedias y las batallas perdidas del pasado como un peso y una deuda, que también son una promesa de redención" (Traverso, 2018, p. 20). Traverso no menciona a Dussel con respecto a este tema. Sin embargo, la categoría víctima para Dussel no se asemeja a lo expuesto por Traverso, por el contrario, la víctima dusseliana posee la potencialidad redentora en el ejercicio de su praxis de liberación. En este sentido, la noción de vencidos de Traverso tiene un sentido similar a la categoría de víctima en Dussel. 
con la condición de despojo y dominación de las víctimas en el capitalismo periférico. Para Dussel, la víctima es quien afirma:

La no-verdad del sistema porque no puede reproducir la vida, y como la vida es el criterio de verdad, al morir dicen: esto no es verdadero. Entonces, desde la noverdad del sistema, yo puedo acceder a un nuevo acceso a la realidad y oponerme a la validez que tiene el poder que me puede matar (Dussel, 2014c, p. 198).

Como dijimos, la Ética de la Liberación comienza su reflexión ético-crítica desde la situación concreta de la víctima. La comunidad de vida (Lebensgemeinschaft) se manifiesta en diversos tipos concretos de interpelación de la víctima: a) la interpelación racial del excluido, b) la interpelación de la mujer hacia el machismo, c) la interpelación del trabajador explotado, d) la interpelación por la responsabilidad de la crisis ecológica, e) la interpelación al eurocentrismo dominante, f) la interpelación económica por la dependencia de los países periféricos, entre otras (Dussel, 2013). Las filosofías de Levinas y Marx, según la perspectiva de Dussel, coinciden en una conciencia ético-crítica que pone en evidencia las múltiples formas de negar la vida del Otro. Como señala el filósofo argentino "la «negatividad» emerge, se presenta, se descubre (es todo el proceso de la «concientización») desde la «positividad» (esto lo vieron Marx y Levinas)" (Dussel, 1998: 370). El sistema vigente aparece como normal y legítimo; las filosofías críticas desnaturalizan la opresión dominante para afirmar la dignidad del Otro. La existencia misma de las víctimas objeta la legitimidad del sistema vigente al revelar la imposibilidad efectiva de la reproducción de su propia vida.

Por tal razón, la labor crítico-positiva se inicia con el reconocimiento de la dignidad inalienable del Otro como sujeto viviente y en virtud de ello se denuncian los actos, prácticas, normas e instituciones que sostienen el sistema vigente. Por tanto, dicho reconocimiento positivo se basa en la dimensión pre-ontológica del Otro como víctima que no logra satisfacer la reproducción de su vida y nos reclama solidaridad.

En suma, la actitud des-colonial dusseliana emprende la crítica a través de la "tarea incesante de dilucidar las formas perversas en que opera la lógica de la colonialidad, como lógica de muerte constitutiva de la modernidad, y de abrir un horizonte donde la vida humana se haga posible en plenitud (Maldonado-Torres, 2018, p. 337). En otras palabras, amparar a la Alteridad de la situación concreta de victimización en sus diversas expresiones materiales. Esencialmente la crítica se muestra en la negatividad material de la víctima como tal, en la imposibilidad efectiva de desarrollar plenamente su vida. Esto muestra el aspecto crítico-negativo que aflige al Otro. El descubrimiento de la existencia fáctica de la víctima se articula desde el reconocimiento de la Alteridad como corporalidad viviente. Dicho reconocimiento subvierte al sistema fetichizado. La lucha por el reconocimiento se constituye como un momento del quehacer crítico. La actividad crítica niega la imposibilidad de la realización vital de la víctima. Es decir, afirma desde el plano deontológico el principio de la ética material para todo sujeto ético. La labor crítico-ética se funda en la conciencia ética de la Alteridad como víctima.

\section{Conclusión}

Recapitulemos, la problemática nodal del pensamiento descolonial dusseliano consiste en reflexionar sobre la Alteridad a través de las categorías de exterioridad, trabajo vivo y víctima. Observamos dos grandes momentos en su pensamiento. En el 
primer momento, el filósofo argentino-mexicano comienza concebirse como latinoamericano desde la lejanía con su patria de origen. Luego, se aproxima a la ética levinasiana con el propósito de conceptualizar de modo abstracto la Alteridad como exterioridad. Posteriormente, expusimos sintéticamente las nociones de Totalidad y Exterioridad en pensamiento ético de Levinas con la finalidad comprender la reapropiación dusseliana de dichas nociones en su filosofía. Según Dussel, la Totalidad aparece como fundamento ontológico del mundo dado, mientras que la exterioridad es anterior y trascendente a la ontología a través de la dis-tinción ana-léctica. Mostramos que Levinas escindía el ámbito ético del político y Dussel reunifica ambos órdenes en la articulación de mediaciones abstractas que se establecen entre la exterioridad y la Totalidad: erótica, pedagógica, política, etc.

En el segundo momento, Dussel en el exilio profundiza su conciencia como latinoamericana y mundializa su concepción de la Alteridad para tematizar concretamente la opresión y exclusión desde las categorías de trabajo vivo y víctima. En estos años, elabora su interpretación sobre obra marxiana y dialoga con la Ética del Discurso. En principio, describimos la dimensión económica y material de la propuesta dusseliana para comprender la Alteridad como trabajo vivo. En la dimensión económica, el trabajo vivo se manifiesta en el pauper como la vida negada por el sistema vigente. La pobreza es concebida como la imposibilidad efectiva de la reproducción humana vital. El trabajo vivo es corporalidad del trabajador que enfrenta al capital. En su dimensión material, se postula el principio material universal que piensa las condiciones de producción, reproducción y desarrollo de la vida de la víctima. Por ello, la existencia misma de las víctimas cuestiona radicalmente la legitimidad del sistema vigente al revelar la imposibilidad efectiva de la reproducción de su propia vida. El mencionado principio se constituye desde una doble faceta: en primer lugar, su faceta negativa en el incumplimiento de la reproducción de la vida, y luego, en su faceta positiva, en el tomar a su cargo la responsabilidad de la Alteridad como víctima para que pueda liberarse y desarrollar íntegramente su vida. El proceso de liberación de la comunidad de víctimas no puede llevarse a cabo por un agente exógeno respecto de la misma. Es responsabilidad intransferible de cada comunidad el asumirse como sujeto de derecho con el fin de realizar el principio material universal de la ética. Por la tanto, el pensamiento descolonial dusseliano es una ética de la vida.

En síntesis, la meditación dusseliana acerca del Alteridad en los '70 se formulaba desde un lenguaje meta-físico abstracto por medio de la categoría de exterioridad. En cambio, a partir del año 1976 en el exilio mexicano la categoría de trabajo vivo subsume concretamente no sólo la de pauper sino también la de exterioridad puesto que su reflexión parte de la materialidad humana. En definitiva, la categoría de víctima nos posibilita comenzar empíricamente desde los tipos concretos de interpelación de la materialidad humana viviente y, a su vez, reconstruir analíticamente los diversos niveles de concreción histórica de la opresión y la exclusión en los países periféricos. 


\section{Referencias bibliográficas}

Acosta, Y. (2019). Interculturalidad y transición a la Transmodernidad. Utopía y Praxis Latinoamericana, (24), 28-42. https://doi.org/http://doi.org/10.5281/zenodo.3108461

Adlbi Sibai, S. (2016). La cárcel del feminismo. Hacia un pensamiento islámico decolonial. Madrid: Ediciones Akal

Ardiles, O., Assman, H., Casalla, M., Cerutti Guldberg, H., De Zan, J., Dussel, E., ... Scannone, J. C. (1973). Hacia una filosofía de la liberación latinoamericana. Buenos Aires: Bonum

Arpini, A. M. (2016). Función y método de una filosofía latinoamericana. La propuesta de Enrique Dussel en el contexto del surgimiento de la filosofía de la liberación. In C. Ibarra Peña, Alex Valdés Norambuena (Ed.), Homenaje a los 80 años de Enrique Dussel. Lecturas críticas (pp. 103-124). Retrieved from https://enriquedussel.com/txt/ Textos_Libros_Sobre_ED/2017.Homenaje_80-Alex_Ibarra_Cristian_Valdes.PDF

Arpini, A. M. (2017). Hecho en el exilio. Etapas en el proceso de ampliación metodológica propuesto por Arturo Andrés Roig. In A. M. Arpini (Ed.), Fragmentos y episodios. Expresiones del pensamiento crítico de. América Latina y el Caribe en el siglo XX (pp. 339-337). Retrieved from https://qell.files.wordpress.com/2018/04/fragmentos-yepisodios-arpini.pdf

Bautista, J. J. (2014). ¿Qué significa pensar desde América Latina? Hacia una racionalidad transmoderna y postoccidental. Madrid: Ediciones Akal.

Benjamin, W. (2009). Tesis sobre la historia y otros fragmentos (B. Echeverría, ed.). Rosario: Prohistoria ediciones.

Beorlegui, C. (2010). La generación de los años setenta. Las filosofías de la liberación. In Historia del pensamiento filosófico latinoamericano. Una búsqueda incesante de la identidad (pp. 661-802). Bilbao: Universidad de Deusto.

Castro-Gómez, S. (2019). El tonto y los canallas notas para un republicanismo transmoderno. Bogotá: Editorial Pontificia Universidad Javeriana.

Césaire, A. (2006). Discurso sobre el colonialismo. Madrid: Ediciones Akal.

Chakrabarty, D. (2008). Al margen de Europa: pensamiento poscolonial y diferencia histórica (1a ed.). Buenos Aires: Tusquets Editores.

Dussel, E. (1998). Ética de la Liberación en la Edad de la Globalización y de la Exclusión. Madrid: Editorial Trotta.

Dussel, E. (2007). El último Marx (1863-1882) y la liberación latinoamericana. México: Siglo Veintiuno Editores.

Dussel, E. (2008). 1492: El encubrimiento del Otro. Hacia el origen del «Mito de la modernidad». La Paz: Biblioteca Indigena Retrieved from https://www.vicepresidencia.gob. bo/IMG/pdf/dussel_.pdf

Dussel, E. (2010). La producción teórica de Marx: un comentario a los Grundrisse. México: Siglo Veintiuno Editores.

Dussel, E. (2011). Filosofía de la Liberación. México: FCE.

Dussel, E. (2012a). Filosofía, aparatos hegemónicos y exilio. In Praxis latinoamericana y filosofía de la liberación (pp. 99-116). Buenos Aires: Docencia. 
Dussel, E. (2012b). Método para una filosofía de la liberación. Buenos Aires: Docencia.

Dussel, E. (2012c). Praxis latinoamericana y filosofía de la liberación. Buenos Aires: Docencia.

Dussel, E. (2013). La razón del Otro. La «interpelación» como acto de habla. In Ética del Discurso y Ética de la Liberación (pp. 141-170). Buenos Aires: Docencia.

Dussel, E. (2014a). Para una ética de la liberación latinoamericana I. México: Siglo XXI editores.

Dussel, E. (2014b). Para una ética de la liberación latinoamericana II. México: Siglo XXI editores.

Dussel, E. (2014c). Ricoeur, Rorty, Taylor y Vattimo ante la Filosofía y la Ética de la Liberación. Buenos Aires: Docencia.

Dussel, E. (2018a). En búsqueda del sentido. Sobre el origen y desarrollo de una Filosofía de la Liberación. Ciudad Autónoma de Buenos Aires: Editorial Las cuarenta.

Dussel, E. (2018b). Una década política argentina (1966-1976) y el origen de la «Filosofía de la Liberación». In En búsqueda del sentido. Sobre el origen y desarrollo de una Filosofía de la Liberación (pp. 119-152). Ciudad Autónoma de Buenos Aires: Editorial Las cuarenta.

Dussel, E., \& Apel, K.-O. (2013). Ética del Discurso y Ética de la Liberación. Buenos Aires: Docencia.

Dussel, E. (2020). Siete ensayos de Filosofía de la Liberación. Hacia una fundamentción del giro decolonial. Madrid: Editorial Trotta.

Fanon, F. (2009). Piel negra, máscaras blancas. Madrid: Ediciones Akal.

Fornet-Betancourt, R. (2001). Enrique Dussel (1934-). In Transformaciones del marxismo. Historia del marxismo en América Latina (pp. 325-351). México: Universidad Nacional Autónoma de Nuevo León; Plaza y Valdés editores.

García Ruiz, P. E. (2003). ¿Evolución o Ruptura? In Filosofía de la liberación. Una aproximación al pensamiento de Enrique Dussel (pp. 19-23). México: Editorial Dríada.

González, M., \& Maddonni, L. (2018). La filosofía de la liberación en su "polo argentino". Aportes para una interpretación histórica y filosófica período 1969-1975. CUADERNOS DEL CEL, 3(5), 63-71. Retrieved from http://www.celcuadernos.com.ar/upload/ pdf/Papeles de trabajo.2.pdf

Guha, R. (2002). Las voces de la historia y otros estudios subalternos. Barcelona: Crítica

Grosfoguel, R. (2008). Hacia un Pluri-Versalismo Transmoderno Decolonial. Tabula Rasa, (9), 199-215. Retrieved from http://www.revistatabularasa.org/numero-9/10grosfoguel. pdf

Grosfoguel, R. (2009). Izquierdas e Izquierdas Otras: entre el proyecto de la izquierda eurocéntrica y el proyecto transmoderno de la nuevas izquierdas descoloniales. Tabula Rasa, (11), 9-29. Retrieved from http://www.revistatabularasa.org/numero-11/presentacion.pdf

Grosfoguel, R. (2016). Del 'extraccionismo económico' al 'extraccionismo epistémico' y al 'extraccionismo ontológico': una forma destructiva de conocer, ser y estar en el mundo. Tabula Rasa, (24), 123-143. https://doi.org/https://doi.org/10.25058/20112742.60 
Grosfoguel, R. (2018). La compleja relación entre modernidad y capitalismo: una visión descolonial. Pléyade Revista de Humanidades y Ciencias Sociales, (21), 29-47. Retrieved from http://www.revistapleyade.cl/wp-content/uploads/2.-Grosfogel_La-compleja-relacion.pdf

Lander, E., \& Quintero, J. (2019). Declaración de la Red de descolonización y autogobierno social. Descolonialidad y Autogobierno , (2), 9-13. Retrieved from https://bit. ly/2yfVTY7

Lander, E., Svampa, M., Segato, R., Escobar, A., Negri, A., Santos, B. de S., ... Tarcus, H. (2019). Declaración internacional. Detener la escalada del conflicto político en Venezuela. Contra la intervención imperial. Por una solución democrática, desde y para el pueblo venezolano. Retrieved February 22, 2019, from Observatorio de Ecología Política de Venezuela website: http://www.ecopoliticavenezuela.org/2019/01/29/ declaracion-internacional-detener-la-escalada-del-conflicto-politico-venezuela/?fbclid =IwAR3ej8HxlikrDzHKQx5U-Rii2jtA-zMwbJ2UfLc4lzx0uRUL-uqe4NCEZ8A

Levinas, E. (2000). Ética e infinito. Madrid: Machado Libros.

Levinas, E. (2002). Totalidad e infinito: ensayo sobre la exterioridad. Salamanca: Ediciones Sígueme.

Löwy, M. (1994). Marx un siglo después. El Rodaballo. Revista de Cultura y Política, (1), 3-17. Retrieved from https://marxismocritico.files.wordpress.com/2011/10/marx-unsiglo-despues.pdf

Löwy, M. (2007). El marxismo en América Latina. Santiago de Chile: LOM Ediciones.

Maldonado-Torres, N. (2007). Sobre la colonialidad del ser: contribuciones al desarrollo de un concepto. In S. Castro-Gómez \& R. Grosfoguel (Eds.), El giro decolonial: reflexiones para una diversidad epistémica más allá del capitalismo global (pp. 127-168).

Maldonado-Torres, N. (2008a). Enrique Dussel's contribution to the de-colonial turn: from the critique of modernity to transmodernity. In Against war: views from the underside of modernity (pp. 187-236). Retrieved from http://93.174.95.29/_ads/ F77271976B29CECF1C57C8E6ABAFA021

Maldonado-Torres, N. (2008b). La descolonización y el giro des-colonial. Tabula Rasa, (9), 61-72. Retrieved from http://www.redalyc.org/articulo.oa?id=39600905

Maldonado-Torres, N. (2018). Intervenciones filosóficas al proyecto inacabado de la descolonizacion. In J. Gandarilla \& M. Moraña (Eds.), Del monólogo europeo al diálogo inter-filosófico. Ensayos sobre Enrique Dussel y la filosofía de la liberación (pp. 313342). México: CEIICH-UNAM.

Martinez Andrade, L., \& Grosfoguel, R. (2013). Hay que tomarse en serio el pensamiento crítico de los colonizados en toda su complejidad. Metapolítica, (83), 38-47. Retrieved from http://www.boaventuradesousasantos.pt/media/Grosfoguel METAPOLITICA_831.pdf

Marx, K. (2018). Comunidad, nacionalismos y capital. Vicepresidencia del Estado Plurinacional de Bolivia. https://www.marxists.org/espanol/m-e/selecciones/marx-comunidadnacionalismos-capital.pdf

Marx, K. (2019). Colonialismo. Cuaderno de Londres N. ${ }^{\circ}$ XIV, 185 (inédito). Vicepresidencia del Estado Plurinacional de Bolivia. 
Marx, K., \& Engels, F. (1979). Imperio y colonia escritos sobre Irlanda. Ediciones de pasado y presente. https://es.scribd.com/document/396357685/ Marx-Engels-Imperio-y-Colonia-Escritos-Sobre-Irlanda

Mignolo, W. (2009a). El lado más oscuro del Renacimiento. Universitas Humanística, (67), 165-203. Retrieved from http://www.scielo.org.co/pdf/unih/n67/n67a09.pdf

Mignolo, W. (2009b). La idea de América Latina (la derecha, la izquierda y la opción decoIonial). CRÍTICA Y EMANCIPACIÓN, (2), 251-276.

Ortega Reyna, J. (2019). Lectura y producción: itinerarios de El Capital en América Latina. Sociología Histórica, (9), 535-563. https://doi.org/https://doi.org/10.6018/sh.298031

Parisí, A. (2005). Diferencia. In R. Salas Astrain (Ed.), Pensamiento crítico latinoamericano. Conceptos fundamentales. Volumen I (pp. 189-200). Retrieved from http:// biblioteca-digital.ucsh.cl/greenstone/collect/libros/index/assoc/HASHd8a7.dir/Pensamiento critico I.pdf

Picotti, D. (1998). La presencia africana en nuestra identidad. Buenos Aires: Ediciones Del Sol.

Quijano, Aníbal. (2014). Cuestiones y Horizontes. De la Dependencia Histórico-Estructural a la Colonialidad/ Descolonialidad del Poder (D. Assis Clímaco, Ed.). Retrieved from https://www.clacso.org.ar/antologias/detalle.php?id_libro=871

Quijano, Aníbal, et al (2017). Llamado Internacional a detener la violencia en Venezuela. Más allá de la polarización. Retrieved February 22, 2019, from http://llamadointernacionalvenezuela.blogspot.com website: http://llamadointernacionalvenezuela.blogspot.com/2017/05/llamado-internacional-urgente-detener_30.html?m=1

Said, E. (1996). Representaciones del intelectual. Buenos Aires: Paidós.

Sánchez, E. G. (2018). En torno a la interpretación categorial de Enrique Dussel sobre Karl Marx. In C. Lértora Mendoza (Ed.), Política, Educación y Sociedad en la Filosofía argentina del Siglo XX (pp. 123-138). Buenos Aires.

Sánchez, E. G., \& Verdini Aguilar, M. P. (2019). 1492 desde el enfoque descolonial de Enrique Dussel. En torno a la producción del colectivo/red Modernidad- Colonialidad. In A. Herrero \& C. Lértora Mendoza (Eds.), Colectivos de pensamiento en temas filosóficos, históricos y políticos: Argentina siglo XX (pp. 89-104). Ciudad Autónoma de Buenos Aires: Ediciones FEPAI.

Spivak, G. (2010). Crítica de la razón poscolonial. Hacia una crítica del presente evanescente. Madrid: Ediciones Akal.

Traverso, E. (2018). Melancolía de izquierda: marxismo, historia y memoria. Ciudad Autónoma de Buenos Aires: Fondo de Cultura Económica.

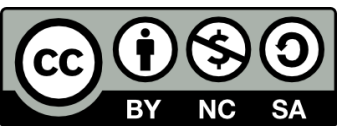

(C) 2021 por el autor. Licencia a ANDULI, Editorial Universidad de Sevilla. Este artículo es un artículo publicado en acceso abierto bajo los términos y condiciones de la licencia Creative Commons Attribution (CC BY) (https://creativecommons.org/ licenses/by-nc-sa/4.0/). 